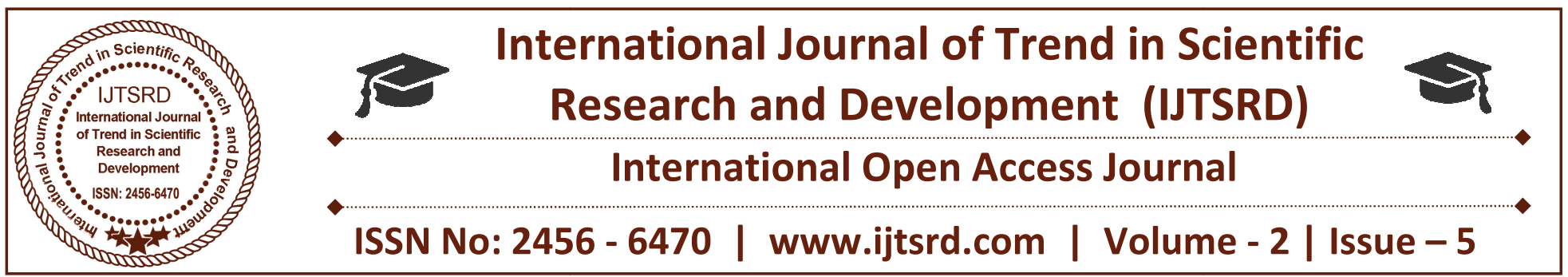

\title{
Cord Blood Mesenchymal Stem Cells Conditioned Media Suppress Epithelial Ovarian Cancer Cells in Vitro
}

\author{
Maher E. Elgaly ${ }^{1,2,5}$, Mohamed E. El Ghareeb ${ }^{1}$, Mohamed H. Bedairy ${ }^{1}$, \\ Ahmed M. Badawy ${ }^{1}$, Abeer Shaaban ${ }^{2,4}$, Farha El shennawy ${ }^{3}$ \\ ${ }^{1}$ Dept of Obstetrics and Gynaecology, Faculty of Medicine, Mansoura University, Mansoura, Dakahlia, Egypt \\ ${ }^{2}$ Institute of Cancer and Genomic Science, Birmingham University, Birmingham B15 2SY, UK \\ ${ }^{3}$ Dept of Clinical Pathology, Faculty of Medicine, Mansoura University, Mansoura, Dakahlia, Egypt \\ ${ }^{4}$ Queen Elizabeth Hospital Birmingham, Birmingham B15 2TH, UK \\ ${ }^{5}$ Royal Wolverhampton Hospital, Wolverhampton Road, Heath Town, WV10 0QP
}

\section{ABSTRACT}

Background and objective: Treatment of epithelial ovarian cancer (EOC) is a major challenge with only $30 \%$ 5-year survival rate. The outcome of the different therapeutic modalities is still poor, and there is an urgency to find new treatment lines. The effect of mesenchymal stem cells on different tumors is greatly variable. The present work shows the effect of cord blood mesenchymal stem cells conditioned media (MSC CM) in different concentrations on epithelial ovarian cancer stem cells (CD44+ cells) in vitro. Methodology: Ovarian cancer stem cells were subjected to MSC CM of $(100 \%, 75 \%, 50 \%, 25 \%)$ concentrations for 72 hours followed by investigation of cell morphology, proliferation, apoptosis, cell cycle and expression of certain genes (Oct-4, Sox-2, and Nanog). Results: Cell shrinkage and cell debris was observed with all cancer cell lines by contrast with control. MTT assay showed a reduction in proliferation, in a concentration-dependent manner. The annexin-v results demonstrated a significant early and late apoptosis. There was an increase in the subG1 phase of the cell cycles indicating apoptosis. There was a progressive suppression of embryonic stemness genes in all cell lines compared to control. Conclusion: Based on these results, it was concluded that MSC CM may be a potential ovarian cancer inhibitor that may create a new modalities of treatment in ovarian cancer patients.

KEYWORD: Cord blood mesenchymal stem cells; ovarian cancer; proliferation, apoptosis; cell cycle analysis; gene expression

\section{INTRODUCTION}

Ovarian cancer is one of the most common female malignancies - worldwide, with an overall 5- year survival rate ranging from 20 to $30 \%$ (Jemal, Murray et al. 2005).The poor outcome of the therapeutic management is partly due to their aggressiveness, metastatic potential, and heterogeneity of the Tumour initiating cell populations (Javazon, Beggs et al. 2004). Bone marrow (BM) was the first source of mesenchymal stem cells (MSC), but isolation from bone marrow is a highly invasive procedure plus the decline in MSC number and differentiation potential with increasing age(He, Ai et al. 2018).There is a plenty of full term umbilical cord blood which can be used without any donor risk as a source of mesenchymal stem cells (UCB-MSCs)(Habibollah, Forraz et al. 2015). Cancer stem cells are multi potent cells that are contributed to the aggressive behavior of ovarian cancer(Long, Xiang et al. 2015, Coffman, Choi et al. 2016)and therapy resistance(Bapat, Mali et al. 2005, Lupia and Cavallaro 2017). Bapat et al. (2005)(Bapat, Mali et al. 2005) succeeded in culturing ovarian cancer stem cells and identified cell surface markers such as stem cell factor, CD44, and Ecadherin.

There are contradictory results of the effects of different mesenchymal stem cells on different tumor types. Tang et al.(Chu, Tang et al. 2015) showed that adipose mesenchymal stem cells accelerate tumour growth, this result was supported by the finding of Cyril Touboul1 et al. (Cyril Touboul1 2013) that 
illustrated recruitments of ovarian cancer cells to areas rich in mesenchymal stem cells through increased expression of IL-6.Guathaman et al.(Gauthaman, Yee et al. 2012) described the suppressive effect of human Wharton'jelly (HWJ) stem cells on epithelial ovarian cancer cell line in vitro. The aim of this research is to study the effect of cord blood mesenchymal stem cells conditioned media (MSC CM) on growth and survival of ovarian cancer cells in vitro. The aim of the use of the conditioned media is to exclude any possible effect due to cell-to-cell contact.

\section{METHODS}

This research was approved by institutional research board (IRB) committee of the faculty of medicine, Mansoura University, Egypt.

A. Preparation of cord blood mesenchymal stem cell conditioned media:

Cord blood was collected after written consents from mothers in Obstetrics and gynecology Department, Mansoura University Hospital, Egypt and ethical approval from Institutional Research Board (IRB) of Mansoura University, Egypt. Isolation of mesenchymal stem cells was done by ficoll-hypaque solution(Clinilab, Egypt) as described before by Bieback, K., et al.(Bieback, Kern et al. 2004). Flow cytometry of the isolated Fibroblast-like cells at passage 3 were analyzed for CD34, CD105 and CD90 using EPICS-XL flow cytometry (Coulter, Miami, Fl). The culture media of passages 3 and 4, $80 \%$ confluence were used for the preparation of MSC CM. The cord blood MSC (passage 3 and 4) were incubated for 72 hours in a culture media consisted of DMEM supplemented with $10 \%$ fetal bovine serum, $1 \%$ penicillin-streptomycin and $1 \%$ L-glutamine (Clinilab, Egypt). The media was filtered by a 0.22 $\mathrm{mm}$ MillexGP syringe filter then serial dilutions were done using ordinary media to produce $75 \%, 50 \%$, $25 \%$ concentrations which are stored at $-80^{\circ} \mathrm{c}$ till using in experiments.

\section{B. Establishment of Primary Epithelial Ovarian Cancer (EOC) cell line:}

Tumor specimen of grade II papillary serous cystadenocarcinoma stage IIIc (confirmed primarily by frozen section then by paraffin section) was taken after a written consent from a patient in the gynecology Department, Mansoura University Hospital, Egypt. Ovarian cancer cells were isolated and prepared as described by Sueblinvong, Ghebre et al, 2012(Sueblinvong, Ghebre et al. 2012).

C. Evaluation of ovarian cancer cells after adding MSC CM:

a. Cell morphology:

Ovarian cancer cells were cultured in 24-well tissue culture plates at a seeding density of $2 \times 10^{4}$ cells/well with MSC CM, with ordinary media used as a control. After 72 hours in culture media, the changes in cell morphology were recorded using an inverted microscope (Nikon Instruments, Tokyo, Japan).

b. MTT assays:

Ovarian cancer cells were incubated in 96 well plate at seeding intensity $1 \times 10^{4}$ cells per well, with MSC $\mathrm{CM}$ at $37^{\circ} \mathrm{C}$ for 72 hours. Ovarian cancer cells in ordinary media were used as a control. After removing the supernatant from each well, aliquot of $20 \mu \mathrm{l}$ of MTT $(5 \mathrm{mg} / \mathrm{ml})$ was added to each well including control, then incubated at $37^{\circ} \mathrm{C}$ until purple precipitates became clearly visible (within 4 hours). $200 \mu \mathrm{g}$ of DMSO were added to each well and the absorbance was measured at a wavelength of $570 \mathrm{~nm}$ using UV spectrophotometer. All experiments were performed in triplicate, and the relative cell viability (\%) was expressed as a percentage relative to the untreated control cells.

c. Annexin $V$ test:

After co-culturing of Ovarian cancer cells with MSC $\mathrm{CM}$, with the use of Ovarian cancer cells in ordinary culture media as a control for 72 hours, Ovarian cancer cells were harvested and incubated with $200 \mu \mathrm{l}$ of annexin binding buffer (PBS supplemented with $2.5 \mathrm{mM} \mathrm{CaCl}_{2}, 5 \mu \mathrm{l}$ of annexin V-FITC and $1 \mu \mathrm{l}$ of PI) at room temperature for $15 \mathrm{~min}$ in the dark, following the manufacturer's instructions. After a final wash in PBS, Ovarian cancer cells were analyzed by flow cytometer (Epics-Altra, Beckman Coulter) and Summit 4.3 (Beckman Coulter).

d. DNA cell cycle analysis with Propidium Iodide $(P I)$ :

Ovarian cancer cells $\left(5 \times 10^{6}\right.$ cells $\left./ \mathrm{ml}\right)$ were cultured with MSC CM for 72 hours with Ovarian cancer cells in ordinary culture media as control. The cells were harvested and washed twice in PBS, then fixed in cold $70 \%$ alcohol for 20 minutes at $-20^{\circ} \mathrm{C}$. The fixed cells were centrifuged at 200x g for 5 minutes to discard the ethanol. To ensure only DNA, not RNA is stained; the cells were treated with ribonuclease (by Adding $50 \mu \mathrm{l}$ of a $200 \mu \mathrm{g} / \mathrm{ml}$ stock of RNase). Finally, $200 \mu \mathrm{l}$ PI (from $50 \mu \mathrm{g} / \mathrm{ml}$ stock solution) was added and incubated in the dark for 30 minutes and then 
analyzed by flow cytometer (Epics-Altra, Beckman Coulter) and Summit 4.3 (Beckman Coulter).

e. Statistical analysis:

All data were expressed as mean $\pm \mathrm{SD}$. The number of experiments (n) used to calculate a mean value was at least 3. An analysis of variance (ANOVA test) was used to compare sample means and to determine statistical significance. All the results were considered statistically significant if $\mathrm{P}<0.05$.

\section{RESULTS}

A. MSC CM preparation

Following 12 trials, isolation of cord blood mesenchymal stem cells was successful (8.3\%success rates). The failure was due to infections $(3 / 12)$, the low yield of cells (6/12), and failure of cell proliferation in culture media. Flow cytometry of the isolated Fibroblast-like cells at passage 4 revealed that the concentrations\% of MSCs were positive for CD105 (85.79 \pm 2.23$)$ and CD90 (92.89 \pm 2.93$)$ and negative for CD34 (1.04 \pm 0.3$)$.

\section{B. Ovarian cancer cells PREPARATION:}

Immediately after separation of cells from ovarian tumor, the percent of viable cells determined by trypan blue test was 25\%. Colonies of epithelial ovarian cancer cells started to appear and spread in the tissue culture plate with progressive disappearance of erythrocytes. By day 14, the EOC cells formed a confluent monolayer.

\section{THE INFLUENCES OF MSC CM ON EPITHELIAL} OVARIAN CANCER CELLS:

a. Morphological examination:

After examination of ovarian cancer cells under low power microscope, we noticed the appearance of many spaces devoid of cells, and this correlated with the concentration of MSC CM as shown in fig. (1). Under high power microscope, the control cells continued to maintain their typical morphology in culture, in contrast to the cancer cells in MSC CM that showed a concentration-dependent decrease in cell numbers, cell shrinkage, cell debris, and many dead cells that were confirmed by trypan blue test.

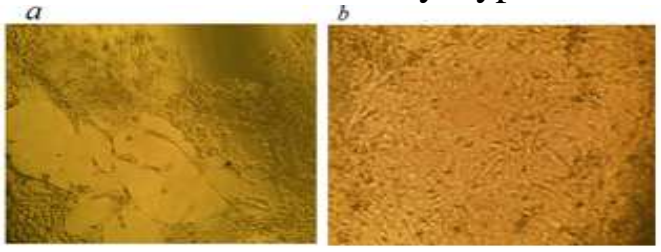

Figure (1): the effect of MSC CM on ovarian cancer cells under microscope a) with MSC CM. b) With control b. MTT assay:

Results demonstrated an inverse relationship between proliferation and concentration of MSC CM. The control cells for $72 \mathrm{~h}$ grew well with no significant inhibition of proliferation, while ovarian cancer cells cultured in MSC CM showed decreases in cell proliferation when compared with control. There was an inhibition by $50.3 \%$ with MSC CM. Cell viability percentages were about $49.6 \%$ in MSC CM concentrations, as demonstrated in fig. (2). The results of MTT assay for all concentration are statistically significant ( $\mathrm{p}$-value $<0.05$ ).

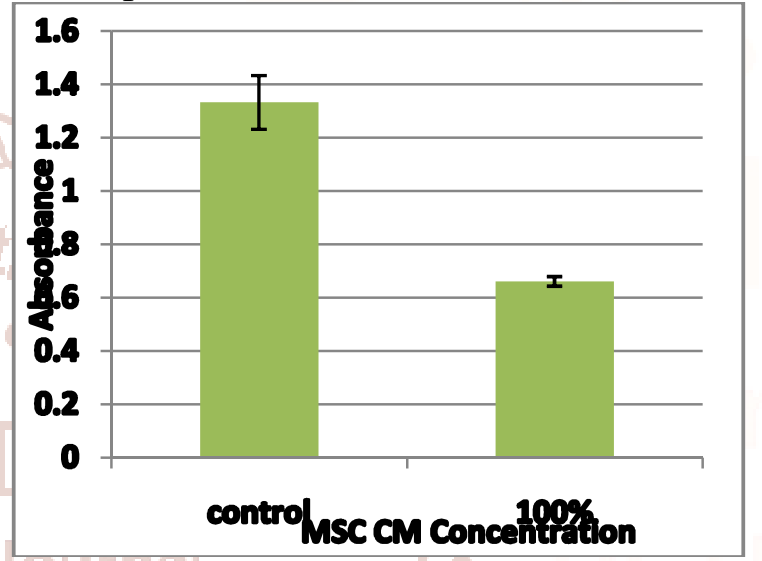

Figure (2): Cell proliferation (MTT assay) of control cell line and CD $44+$ cells cultured in MSC CM (25\%, $50 \%, 75 \%$, and $100 \%$ ) for $72 \mathrm{~h}$. All values were expressed as mean \pm SEM from three different replicates.

c. Annexin V:

When cells were treated with MSC CM, early apoptosis was $\sim 49 \%$ and late apoptosis was $64 \%$. In comparison, the early and late apoptosis rate in the control cells were $1.5 \%, 3.9 \%$ respectively ( $\mathrm{p}$-value $<$ $0.004)$, as shown in fig. (3).
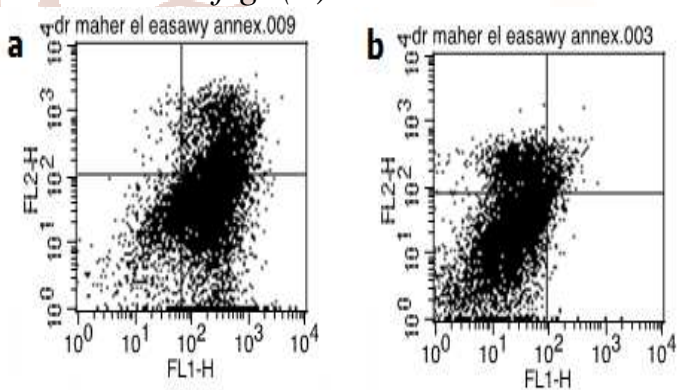

Figure (3): the results of ANNEXIN V test, there is an increase in apoptosis with MSC conditioned media a) annexin with MSC CM b) with control

d. Cell cycle analysis:

The control cells showed their normal typical cell cycle profile. The increase in sub-G1phase for conditioned media concentration was $(72 \%)$, in contrast to $22 \%$ for control as shown in fig (4). 

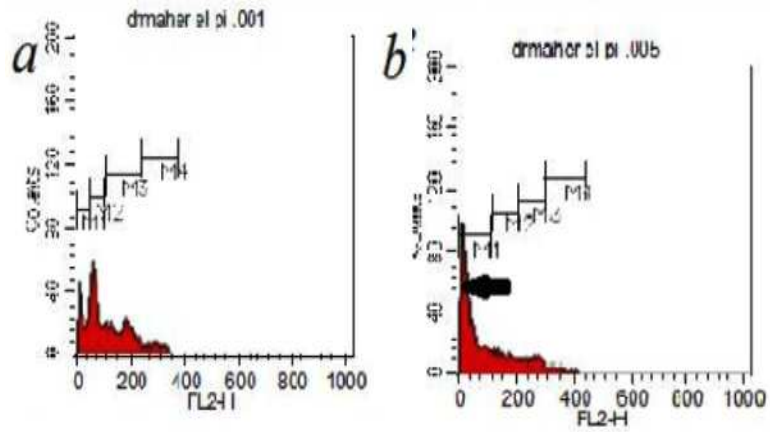

Figure (4): Representative cell cycle flow cytometry images of human ovarian cancer cell lines a)ovarian cancer cells cultured in control culture medium $(b)$ with MSC CM Arrows point out the increased peaks in the sub-G1 phase representing apoptosis in the cancer cell lines compared to the control.

\section{Discussion:}

There was a gradual suppressions of ovarian cancer cells With MSC CM in vitro and this suppressions were statistically significant $(\mathrm{p}<0.05)$. This effect is very hopeful in creation of new research era and different therapeutic modalities away from traditional major surgeries and unpleasant side effects of chemotherapies. Our study shows the indirect effect of cord blood mesenchymal stem cells and excludes any possible roles of direct cell-cell contact. IL-6 was shown to be responsible for such inhibitory effects (Cyril Touboul1 2013) but, further researches is still required to confirm and identify other factor.

Isolation of mesenchymal stem cells (MSCs) from full-term umbilical cord blood (UCB) is a timeconsuming process and results in a low yield of cells (Bongso and Fong 2013). MSCs were successfully isolated in our research after 12 trials (8.3\% success rates), and this success rate is lower than previously described: $10 \%$ with sibov et al.(Sibov, Severino et al. 2012) and 63\% with Bieback et al. (Bieback, Kern et al. 2004). In general, this low yield of cells may be explained by two main factors: low amount of MSCs in umbilical cord blood and the presence of clots and hemolysis (Sibov, Severino et al. 2012). Several automated methods instead of ficoll can be used (as Sepax and automated processing platform(AXP)) (Badowski and Harris 2012). Cell counts obtained in the final Ficoll product are generally half the cell counts of the Sepax and AXP, although the stem cell recovery may be similar (Chow 2015).

Sueblinvong et al. (Sueblinvong, Ghebre et al. 2012) stated that enzymatic digestion for 30 minutes with dispase II resulted in higher recovery of viable epithelial ovarian cancer cells, compared to mechanical disruption (58\% versus $19.9 \%$ ), but, prolonged exposure to enzymatic digestion is accompanied by significant decrease in the recovery of viable cells.

The results of MTT assay agreed with that of Guathaman et al. (Gauthaman, Yee et al. 2012) that reported inhibition by $2.05 \%, 3.44 \%$, and $8.67 \%$ for $50 \%, 75 \%$ and $100 \%$ of conditioned media concentrations respectively, although their values were not statistically significant. Tang et $\boldsymbol{a l}$. (Chu, Tang et al. 2015) investigated the effect of mesenchymal stem cell derived from adipose tissue on epithelial ovarian cancer cells in vitro and found a 2 -fold increase in proliferation rate in direct culture and a 5-fold increase in indirect culture ( $p$ value $=0.001$, and explained this effects by the increased levels of matrix metalloproteinases (MMPs).

Our results were similar to the study done by Guathaman et al. (Gauthaman, Yee et al. 2012), that showed increase in annexin V-FITC positive cells when cultured with human Wharton jelly stem cell (HWJSC) Condition media $(50 \%)$ and HWJSC cell lysate $(15 \mathrm{mg} / \mathrm{ml}$ protein) compared to the respective controls. The increase in HWJSC -CM (50\%) was $4.06 \%$. In contrast to cord blood mesenchymal stem cells, adipose-derived mesenchymal stem cells were associated with increased invasiveness of epithelial ovarian cancer for both direct and indirect co-culture (Chu, Tang et al. 2015).

The increase in peaks of the sub-G1 phase and positive annexin V-FITC staining explain the MSC $\mathrm{CM}$ anti-cancer effect. The increases in sub-G1 phase for TOV-112D was $5.01 \%, 9.41 \%$ for $50 \%$ conditioned media and hWJSC-CL $(15 \mathrm{mg} / \mathrm{ml}$ protein) in Guathaman study respectively, (Gauthaman, Yee et al. 2012). In the study of Cyril Touboul1et al. (Cyril Touboul1 2013)the ovarian cancer cells were recruited to the areas of mesenchymal stem cell derived from the fetal membrane in a 3D-designed peritoneal model due to high levels of IL-6.

\section{CONCLUSION:}

MSC CM has an inhibitory effect on ovarian cancer cell line in vitro. The increased peaks in the sub-G1 phase, positive annexin V-FITC staining, may explain this suppressive effect. 
This work was supported by Mansoura experimental research center and Mansoura regenerative medicine.

\section{REFERENCES}

1. Jemal A, Murray T, Ward E, Samuels A, Tiwari RC, Ghafoor A, et al. Cancer statistics, 2005. CA Cancer J Clin. 2005; 55(1):10-30.

2. Javazon EH, Beggs KJ, Flake AW. Mesenchymal stem cells: paradoxes of pass aging. Exp Hematol. 2004; 32(5):414-25.

3. He X, Ai S, Guo W, Yang Y, Wang Z, Jiang D, et al. Umbilical cord-derived mesenchymal stem (stromal) cells for treatment of severe sepsis: a phase 1 clinical trial. Translational Research. 2018.

4. Habibollah S, Forraz N, McGuckin CP. Application of Umbilical Cord and Cord Blood as Alternative Modes for Liver Therapy. Regen Med: Springer; 2015. p. 223-41.

5. Coffman LG, Choi Y-J, McLean K, Allen BL, di Magliano MP, Buckanovich RJ. Human carcinoma-associated mesenchymal stem cells promote ovarian cancer chemotherapy resistance via a BMP4/HH signaling loop. Oncotarget. 2016; 7(6):6916.

6. Long H, Xiang T, Qi W, Huang J, Chen J, He L, et al. CD133+ ovarian cancer stem-like cells promote non-stem cancer cell metastasis via CCL5 induced epithelial-mesenchymal transition. Oncotarget. 2015; 6(8):5846.

7. Bapat SA, Mali AM, Koppikar CB, Kurrey NK. Stem and progenitor-like cells contribute to the aggressive behavior of human epithelial ovarian cancer. Cancer Res. 2005; 65(8):3025-9.

8. Lupia M, Cavallaro U. Ovarian cancer stem cells: still an elusive entity? Mol Cancer. 2017;16(1):64.

9. Chu Y, Tang H, Guo Y, Guo J, Huang B, Fang F, et al. Adipose-derived mesenchymal stem cells promote cell proliferation and invasion of epithelial ovarian cancer. Exp Cell Res. 2015; 337(1):16-27.

10. Cyril Touboul1, Raphael Lis1,3†, Halema Al Farsi1, Christophe M Raynaud1, Mohamed Warfa1, Hamda Althawadi1, Eliane Mery4, Massoud Mirshahi2 and Arash Rafii1,. <14795876-11-28.pdf>. 2013.

11. Gauthaman K, Yee FC, Cheyyatraivendran S, Biswas A, Choolani M, Bongso A. Human umbilical cord wharton's jelly stem cell (hWJSC) extracts inhibit cancer cell growth in vitro. J Cell Biochem. 2012; 113(6):2027-39.

12. Bieback K, Kern S, Klüter H, Eichler H. Critical parameters for the isolation of mesenchymal stem cells from umbilical cord blood. Stem Cells. 2004; 22(4):625-34.

13. Sueblinvong T, Ghebre R, lizuka Y, Pambuccian SE, Vogel RI, Skubitz AP, et al. Establishment, characterization and downstream application of primary ovarian cancer cells derived from solid tumors. PLoS One. 2012; 7(11):e50519.

14. Najafzadeh N, Mazani M, Abbasi A, Farassati F, Amani M. Low-dose all-trans retinoic acid enhances cytotoxicity of cisplatin and 5fluorouracil on CD44+ cancer stem cells. Biomed Pharmacother. 2015; 74: 243-51.

15. Bongso A, Fong C-Y. The therapeutic potential, challenges and future clinical directions of stem cells from the Wharton's jelly of the human umbilical cord. Stem Cell Reviews and Reports. 2013; 9(2):226-40.

16. Sibov TT, Severino P, Marti LC, Pavon LF, Oliveira DM, Tobo PR, et al. Mesenchymal stem cells from umbilical cord blood: parameters for isolation, characterization and adipogenic differentiation. Cytotechnology. 2012; 64(5):51121.

17. Bieback K, Kern S, Kluter H, Eichler H. Critical parameters for the isolation of mesenchymal stem cells from umbilical cord blood. Stem Cells. 2004; 22(4):625-34.

18. Badowski MS, Harris DT. Collection, processing, and banking of umbilical cord blood stem cells for transplantation and regenerative medicine. Somatic Stem Cells: Springer; 2012. p. 279-90.

19. Chow R. Blood cell preparations and related methods (gen 8). Google Patents; 2015.

20. Sueblinvong T, Ghebre R, lizuka Y, Pambuccian $\mathrm{SE}$, Isaksson Vogel $\mathrm{R}$, Skubitz $\mathrm{AP}$, et al. Establishment, characterization and downstream application of primary ovarian cancer cells derived from solid tumors. PLoS One. 2012; 7(11):e50519.

21. Bartakova A, Michalova K, Presl J, Vlasak P, Kostun J, Bouda J. CD44 as a cancer stem cell marker and its prognostic value in patients with ovarian carcinoma. J Obstet Gynaecol. 2017:1-5. 
22. Xu C-X, Xu M, Tan L, Yang H, Permuth-Wey J, 24. ElMoneim HMA, Zaghloul NM. Expression of EKruk PA, et al. MicroRNA miR-214 regulates ovarian cancer cell stemness by targeting p53/Nanog. J Biol Chem. 2012; 287(42):34970-8.

23. Ye F, Li Y, Hu Y, Zhou C, Hu Y, Chen H. Expression of Sox2 in human ovarian epithelial cadherin, N-cadherin and snail and their correlation with clinic pathological variants: an immunehistochemical study of 132 invasive ductal breast carcinomas in Egypt. Clinics. 2011; carcinoma. J Cancer Res Clin Oncol. 2011; 137(1):131-7. 66(10):1765-71.

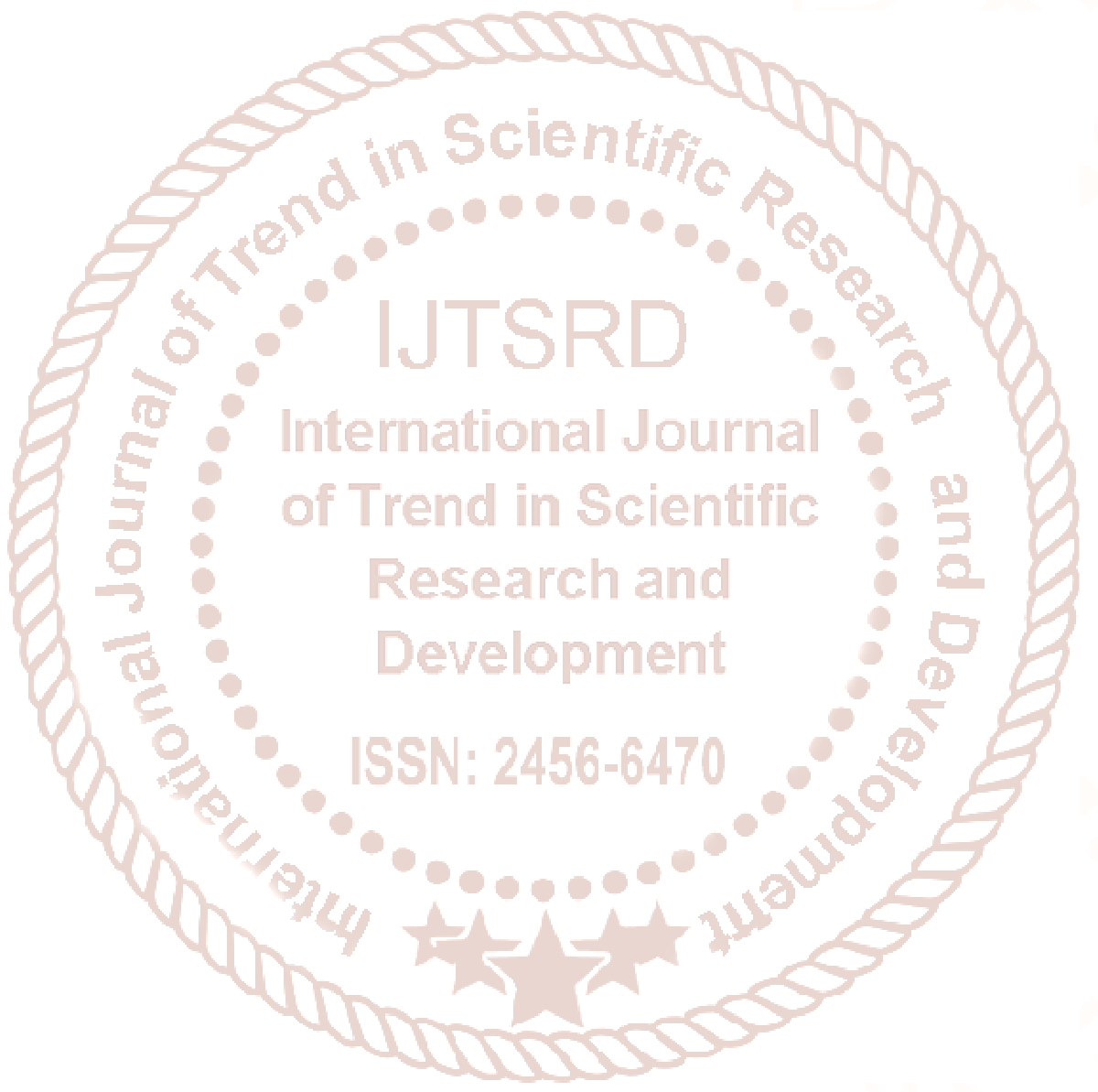

